\section{Usefulness of the Health of the Nation}

\section{Outcome Scales ${ }^{\dagger}$}

\author{
G. S. STEIN
}

subjects with personality disorder present to the services, while many of those suffering from psychoses may be stable or even asymptomatic.

\section{HONOS IN THE NATIONAL HEALTH SERVICE}

Purchasers and managers need to know what their local service requirements are. A critical issue is therefore how well HoNOS scores correlate with service variables. Trauer et al (1999, this issue) examined two specific service variables: contacts with the keyworker and bed utilisation. They found that the frequency of contact with the keyworker correlated poorly with HoNOS scores, so that less than $10 \%$ of the variance in the frequency of contact was explained by the HoNOS score. However, bed utilisation showed a good correlation with high scores on four of the HoNOS sub-scales: Aggression, Cognitive impairment, Hallucinations and delusions, and Impaired activity of daily living. This is an important finding, needing replication, because any measure which can predict the need for hospital beds, (by far the most expensive item in any psychiatric service) may help contribute to more effective planning.

With reliability and validity established, Wing et al (1998) suggested that the next logical step in the development of the HoNOS scale was to see how well it fared in the hands of NHS keyworkers in an invivo situation, and this question has been addressed in the studies of Bebbington et al (1999), Amin et al (1999), Sharma et al (1999) and Orrell et al (1999), all published in this issue.

Bebbington and his colleagues compared keyworkers' HoNOS ratings with research workers' ratings in two busy urban psychiatric services in London and Leicester. In general their results were disappointing, and correlations between keyworker ratings and research worker ratings were poor; rather worse in London than in Leicester (which might be more an indication of the greater pressures on the London services rather than due to any intrinsic defect of the rating scale). However, these findings do not augur well for a more wholesale introduction of HoNOS into routine NHS practice.

Examining a group of subjects with first-onset psychoses some three years after initial presentation, Amin et al paint a 
rather more positive picture. Correlations between the keyworkers and research workers were slightly better, especially for the total score and behaviour items, although they were poor for the social items such as accommodation and employment, which other studies such as Orrell et al (1999, this issue) have also found to be the least reliable of the HoNOS items.

The study by Dr V. K. Sharma and colleagues in Liverpool is of particular importance to NHS consultants, because Dr Sharma appears to be the only NHS consultant to have administered these scales himself to patients under his care, and to have evaluated their utility as well as their validity in his service (Sharma et al, 1999 this issue). They found that patients with affective disorder and schizophrenia showed a significant decline in their HoNOS scores following a hospital admission, and that a change in the HoNOS score showed some correlation with changes in the Clinical Global Impression scale (CGI) (Guy, 1976). However, they found that the HoNOS ratings contributed little to care plans, and were completed almost as an afterthought in the care plan review meeting. In the original studies of Wing et al (1998), the HoNOS scores correlate well with Brief Psychiatric Rating Scale (BPRS) scores, while Amin et al (1999, this issue) also found a good correlation with the World Health Organization Schedules for Clinical Assessment in Neuropsychiatry (SCAN) in a cross-sectional study. However, Bebbington et al (1999, this issue) found no correlation with 'change' scores between the HoNOS and the SCAN, while Sharma et al (1999, this issue) find that changes in HoNOS have to be very large to show scores parallel with changes in the CGI. Thus the CGI categories 'much better' and 'worse' could be separated on the basis of HoNOS ratings, but the categories 'better' and 'no change' could not. HoNOS, therefore, may not be all that sensitive to change, unless the change is quite large, and so its place as a long-term monitoring instrument or as an indicator of the effectiveness of a particular intervention may be limited.

If the scale is to enter routine NHS practice, it must contribute directly to care planning, or otherwise it will remain solely a research instrument. Only time and experience in widely differing NHS settings will determine its use in the longer term, but a comparison with a needs assessment instrument may help gauge the relevance of HoNOS to care planning. Slade et al
(1999, this issue) compared HoNOS to the Camberwell Assessment of Need Short Appraisal Schedule (CANSAS) and used a rather complex factor analysis to extract factors from the CANSAS which corresponded to HoNOS items; these showed a reasonable correlation. The needs identified by the CANSAS are, however, all highly specific, leading directly to interventions, and so might make a contribution to care planning, whereas HoNOS provides only a global score and a general indication of the area of pathology. Slade et al (1999, this issue) felt the HoNOS was insufficiently specific to assist in the care plan of an individual patient - an observation which echoes the experience of Sharma et al (1999, this issue), namely, that HoNOS did not help with the care planning assessment review for individuals, but might still have a role in describing the pathology and needs of groups of patients.

\section{HoNOSCA AND HoNOS 65+}

A parallel development to the adult HoNOS scale has been the development of the Health of Nation Outcome Scale for Children and Adolescents (HoNOSCA). This scale has a similar structure to that of the adult version, and covers sufficiently wide diagnostic and age ranges to enable most of the children presenting to a child psychiatry service to be rated. Core items on this scale are more appropriate to child psychiatry, and include overactivity and attentional disorder, scholastic difficulties, peer group relationship, family relationships and so forth. Gowers et al (1999) report in this issue that the scale is both psychometrically sound and sensitive to change. Gratifyingly, group scores seem to move in the expected direction, in-patients scoring more than out-patients, higher total scores reflecting greater severity, attention deficit improving with age, and depression scores increasing with age. A favourable assessment of the HoNOSCA is also given by Yates et al (1999), but these authors also comment that the all-important social variables of child psychiatry are barely touched on in it. They compared the HoNOSCA to their own instrument, the Paddington Complexity Scale, which covers the main social factors relevant to child psychiatry, but only has a single diagnostic item to cover clinical disturbance, in comparison to the symptom-based items in the HoNOSCA. Correlations between HoNOSCA and other child psychiatry global scales such as the Paddington Scale and the Child Global Assessment Scale (Shaffer et al, 1983) were reasonable (0.6). However, correlations with a more specific child psychiatry rating scale were poor, possibly because the HoNOSCA assessment of symptoms is not very detailed. Yates et al (1999, this issue) felt HoNOSCA had two specific applications, first as an outcome measure, and second, for use in units lacking any medical personnel, where a simple method of appraising symptoms might substitute for a more formal diagnostic approach.

HoNOS $65+$ is a new scale specifically designed for use among the elderly and is published for the first time in this issue of the journal (Burns et al, 1999). We have also published all three HoNOS scales together with their detailed instructions as to how the rating should be made, so that these scales may be readily accessible to interested clinicians. The HoNOS 65+ shares a similar structure to the other HoNOS scales having 12 items each rated on a $0-4$ severity scale, but there is more emphasis on medical disorders and cognitive impairment, as these items are of greater relevance in a psychogeriatric population. In their initial report, the authors claim acceptable validity and reliability for the new scale, but a correlation of -0.23 between the HoNOS 65+ item of cognitive impairment and a similar measure on the Mini-Mental State Examination must throw some doubt on these claims. As with children, the rating of the elderly is often problematical because subjects often cannot give a satisfactory account of their difficulties, making the need for objective and reliable assessment instruments rather more important for psychogeriatric patients.

Like the adult version, both HoNOSCA in children and HoNOS $65+$ in the elderly were used successfully by non-medical mental health professionals and could be completed in less than 10 minutes. Because child psychiatry and psychogeriatric assessments are often lengthy and there are even fewer systematic data available concerning both these groups, HoNOSCA and HoNOS $65+$ may prove to be of greater value than their adult counterpart.

\section{WILLTHE SCALE ENTER ROUTINE PRACTICE?}

Although one of the original aims of drawing up the HoNOS was its use in 
routine NHS practice, this is unlikely to occur. Even if the scale were near-perfect, few clinicians would use it in their day-to-day practice, and there are several reasons for this. The most important relates to its utility, which is a sub-type of validity, and this has yet to be established. Feinstein (1967), writing more than 30 years ago on the utility of classificatory schemes, wrote: "The care of the patient is the ultimate specific act that characterizes the clinician, and any classificatory system that cannot help in that will fail to gain acceptance". He stressed that unless a clinician believes that an intervention would directly help the patient in the consulting room, or, at the very least, assist in the diagnostic process, the intervention will not be undertaken. Time spent between clinicians and patients is highly valued by both parties, and may even be highly charged emotionally with its sole purpose of trying to help the patient. To complete a rating scale which has an ulterior motive such as assisting a purchaser, or helping to gather national statistics, is to act on behalf of third parties. It would therefore serve as an intrusion into the clinician-patient relationship and would not be tolerated except for a very brief period, for example in a research project. The published work on HoNOS also suggests that as soon as the research workers departed, clinicians involved in the research stopped using the scale (Curtis \& Beevor, 1995).

Clinicians of today have a bewildering array of measuring instruments at their disposal, each with an impressive-sounding title and an even more catchy abbreviation. Most have an acceptable reliability and validity, and their protagonists claim that their scales are all about to enter routine clinical practice in the very near future, yet somehow none has ever done so outside a designated research setting.

The term 'Health of the Nation Outcome Scales', by marrying two quite unrelated concepts, namely statehood and

GEORGE S. STEIN, FRCPsych, Por tnalls Unit, Farnborough Hospital, Farnborough Common. Orpington. Kent BR6 8ND

(First received 21 October 1998, accepted 2 December 1998)

mental health, elicits a mild degree of patriotic sentiment, and this has undoubtedly helped to attract both interest and funding. In reality, the HoNOS is yet another symptom and social function inventory, better than most because it is the most relevant to present-day health services. It has also been the most thoroughly researched, and has the advantage of not being diagnostically specific, so that most patients can be rated.

Though the scale is unlikely to enter routine NHS practice, it may come to play a major role in service research. With governments frequently changing policy and direction, there is now an even greater need to monitor the effect of these politically inspired changes. More mundane issues such as whether day hospitals can substitute for in-patient units, how patients fare in hostels, or comparing psychiatric morbidity in different geographical areas, and a host of other service-related issues may also benefit from the new scale. Eventually the HoNOS will find its place within the research armamentarium, but whether it will improve the mental health of this nation or any other nation remains open to question.

\section{REFERENCES}

Amin, S., Singh, S. P., Goudace, T., ef of (I9e9) Evaluating the Health of the Nation Outcome Scales: reliability and validity in a three-year follow-up of firstonset psychosis. British journol of Psychiotry. 174, 399403.

Bebbington, P., Brughan, T., Hill, T., et ol (1999) Validation of the Health of the Nation Outcome Scales (HoNOS). British journal of Psychiatry, 174, 389-394.

Burns, A., Beevor, A., Lelliott, R., et of (1999) Health of the Nation Outcome Scales for Elderly People
(HoNOS 65+). British journal of Psychiatry, 174, 424 427.

Curtis, R. \& Beevor, A. (1995) Health of the Nation Outcome Scales. In Measurement for Mentol Health (ed. J. K.Wing), Ch. 3, pp. 33-47. London: Gaskell.

Endicott, J., Spitzer, R. L., Fleiss, J. L., et al (1976)

The Global Assessment Scale. Archives of General Psychiatry, 33, 766-771.

Epstein, A. M. (1990) The outcome movement - Will it get us where we want to go? New England journal of Medicine, 323, 266-270.

Feinstein, A. R. (1967) Clinicol Judgement. Baltimore, MD: Williams and Wilkins.

Gowers, S. G., Marrington, R. C., Whitton, A., et of (1999) Brief scale for measuring the outcomes of emotional and behavioural disorders in children. Health of the Nation Outcome Scales for Children and Adolescents (HoNOSCA). British journal of Psychiotry. 174, 413-416.

Guy, W. (1976) ECDEU Assessment Manuol for Psychophormacology. Rockville. MD: National Institute of Mental Health.

Orrel, M., Yand, R., Handyaides, J. \& Schapira, R. (1999) Validity and reliability of the Health of the Nation Outcome Scales in psychiatric patients in the community. British journal of Psychiatry, 174, 409-412.

Shatfer, D., Gould, M. S., Brask, J., et ol (1983) Children's Global Assessment Scale (CSAs). Archives of Generol Psychiatry, 40. 1228-1231.

Sharma, V. K., Wilkinson, G. \& Fear, S. (1999) Health of the Nation Outcome Scales: a case study in general psychiatry. British fournol of Psychiotry, 174. 395-398.

Stade, M., Beck, A., Bindman, J., ec ol (1999) Routine clinical outcome measures for patients with severe mental illness: CANSAS and HoNOS. British fournol of Psychiotry. 174. 404-408.

Traver, T., Callahy, T., Hantz, P., et of (1999) Health of the Nation Outcome Scales. Results of the Victorian field trial. British journal of Psychiatry. 174, 380-388.

Wing, J. K., Beevor, A. S., Curtls, R. H., et of (1998) Health of the Nation Outcome Scales: research and development. British journal of Psychiotry, 172, 11-18.

Yates, P., Garralda, M. E. \& Higginson, J. (1999) Paddington Complexity Scale and Health of the Nation Outcome Scales for Children and Addescents. British journal of Psychiatry, 174, 417-423. 